\title{
Differential hippocampal protein expression between normal aged rats and aged rats with postoperative cognitive dysfunction: A proteomic analysis
}

\author{
YANG LI ${ }^{1}$, SAIYING WANG ${ }^{1,2}, \mathrm{KE} \mathrm{RAN}^{3}$, ZHONGHUA HU $^{1}$, ZHAOQIAN LIU ${ }^{2}$ and KAIMING DUAN ${ }^{1}$ \\ ${ }^{1}$ Department of Anesthesiology, Third Xiangya Hospital of Central South University, Changsha, Hunan 410013; \\ ${ }^{2}$ Institute of Clinical Pharmacology, Central South University, Changsha, Hunan 410008; ${ }^{3}$ Department of Anesthesiology, \\ Second Xiangya Hospital of Central South University, Changsha, Hunan 410011, P.R. China
}

Received April 14, 2014; Accepted January 15, 2015

DOI: $10.3892 / \mathrm{mmr} .2015 .3697$

\begin{abstract}
The aim of the present study was to investigate the differences in the expression of hippocampal proteins between normal control aged rats and aged rats with postoperative cognitive dysfunction (POCD). A total of 24 aged rats were randomly divided into a surgery group $(n=12)$ and a control group $(n=12)$. The rats in the surgery group were treated with $2 \mathrm{~h}$ isoflurane anesthesia and splenectomy, while the rats in the control group received $40 \%$ oxygen for $2 \mathrm{~h}$ without surgery. The cognitive functions of the two groups were examined using a Y-maze test. The protein expression profiles of the hippocampus of six aged rats (three rats with POCD and three from the normal control group) were assessed using two-dimensional gel electrophoresis and matrix-assisted laser desorption/ionization time of flight mass spectrometry. A total of three differential proteins were further confirmed between the POCD rats and normal rats using reverse transcription quantitative polymerase chain reaction (RT-qPCR). The expression levels of 21 proteins in the rats with POCD were significantly different compared with the normal control rats. These proteins were functionally clustered to synaptic plasticity (three proteins), oxidative stress (four proteins), energy production (six proteins), neuroinflammation (three proteins) and glutamate metabolism (two proteins). In addition, three proteins (fatty acid binding protein 7 , brain, glutamate dehydrogenase 1 and glutamine synthetase), associated with astrocytic function, were significantly different in the rats with POCD compared with those in the normal control $(\mathrm{P}<0.05)$. Similar changes in the mRNA expression levels of the three proteins in the hippocampi of POCD rats were also detected
\end{abstract}

Correspondence to: Professor Kaiming Duan, Department of Anesthesiology, Third Xiangya Hospital of Central South University, 138 Tong Zipo Road, Changsha, Hunan 410013, P.R. China E-mail: duankaiming@126.com

Key words: postoperative cognitive dysfunction, proteomics, aged rat, astrocyte using RT-qPCR. Neuroinflammation, glutamate toxicity and oxidative stress were possibly involved in the pathological mechanism underlying POCD in aged rats. In addition, astrocytes may also be imporant in POCD in aged rats.

\section{Introduction}

Postoperative cognitive dysfunction (POCD) is characterized by a decline of cognitive performance following surgery, particularly following surgery of aged patients (1). It has been identified to occur in $30-80 \%$ of aged patients 1 week after surgery and in $10-15 \%$ of aged patients 3 months after surgery (2-4). A number of risk factors for POCD have been reported in previous studies, including advanced age, educational level, mental illness, preoperative level of recognition, operative type, and postoperative infection $(4,5)$. However, the pathological mechanisms underlying POCD remain to be elucidated. The toxicity of anesthetics was initially assessed, with simple anesthesia impairing the learning and memory of aged rats (1,6-8) and mice (9). Notably, the duration and type of anesthesia had no significant effects on the incidence of POCD of aged patients at the late stage ( $>1$ week post surgery) (10). This suggested that anesthetics were not important in POCD associated with aged patients. In addition to surgery and anesthesia, another potential mechanism underlying POCD is inflammation induced by surgery. He et al (11) and Wang et al (12) reported that surgical trauma under general anesthesia causes distinct changes in systemic and central pro-inflammatory cytokines in aged rats at an early stage ( $<1$ week post surgery), corresponding closely to the dysfunction of cognition. Open tibial fractures impair the cognitive function and induce the increase of tumor necrosis factor- $\alpha$ (TNF- $\alpha$ ) and interleukin-1 (IL-1) in adult mice $(4,13)$. Inhibiting the signals of TNF- $\alpha$ and IL-1 prior to surgery partly rescued the cognitive dysfunction induced by surgery $(4,13)$. However, a similar incidence of POCD has been detected among aged patients 3 months after surgery, although the extent of the damage induced by surgery was independent of the anaesthetic and the type of surgery (14). This suggested that, in addition to the toxicity of anesthetics and inflammation induced by surgery, other unknown factors also contribute to POCD in aged patients. 
The combination of mass spectrometry and two-dimensional gel electrophoresis is a useful method to examine the differential protein expression levels between different treatments. It is usually used to examine novel mechanisms underlying certain diseases (15). The hippocampus is an important structure, closely involved with learning and memory $(16,17)$. During normal aging, the volume of the hippocampus decreases gradually, particularly the dentate gyrus and the CA3 area $(18,19)$. During pathological aging, as observed in Alzheimer's disease, the hippocampal volume decreases more rapidly $(18,19)$. Accordingly, Chen et al (20) found that the hippocampal volume in aged patients with POCD is significantly smaller compared with that of aged patients without POCD (20). In addition, the hippocampal volume was negatively correlated with the score of cognitive function of aged patients. These suggested that changes in the volume of the hippocampus were closely involved in the occurrence of POCD in aged patients. In the present study, differences in the protein expression of the hippocampus were compared between aged rats with POCD and normal aged rats.

\section{Materials and methods}

Animals and grouping. A total of 24 aged male Sprague-Dawley rats (22 months old) were purchased from the Experimental Animal Nursery of Central South University (Changsha, China). The rats were maintained under temperature-controlled environmental conditions with a 12/12-h light/dark cycle and had ad libitum access to food and water. The food consisted of standardized rodent pellets. Ambient conditions remained constant at $23^{\circ} \mathrm{C}$ and a relative humidity of $50-60 \%$. All procedures were approved by the Medical Ethics Committee of the Third Xiangya Hospital of Central South University and conformed to the guidelines for animal experiments of Central South University.

A total of 24 rats were handled, according to the flow chart of the study design shown in Fig. 1. The rats were divided randomly into a surgery group $(\mathrm{n}=12)$ and a normal control group $(n=12)$. The rats in the surgery group were treated with isoflurane anesthesia for $2 \mathrm{~h}$ and splenectomy, while rats in the normal control group received $40 \%$ oxygen for $2 \mathrm{~h}$ without surgery (1). The cognitive functions of the two groups were examined using a Y-maze test. The upper limit of the $95 \%$ confidence interval of the mean training duration of rats in the normal control group in the Y-maze test was used to decide whether the rats in the surgery group had cognitive dysfunction (21). The rats in the surgery group were subdivided into POCD and no-POCD groups, according to previously described methods (21). The protein profile from the hippocampi of six aged rats (three rats with POCD and three rats from the normal control group) were detected using two-dimensional gel electrophoresis (2-DE) and matrix-assisted laser desorption/ionization time of flight mass spectrometry (MALDI-TOF-MS).

Y-maze test. The details of the Y-maze assessment (Fig. 2) was described in our previous study (1). Briefly, the voltage for the electric shock in the Y-maze was $50 \pm 5 \mathrm{~V}$. The rats were acclimatized to the Y-maze with the light on for $3 \mathrm{~min} 24 \mathrm{~h}$ after treatment. Subsequently, the rats were placed in the stem arm and were administered an electric shock. If the rats arrived at the lit arms within $30 \mathrm{sec}$, the trial was deemed successful. The same trial was repeated 20 times/day consecutively for 3 days. During the assessment, the following parameters were recorded: The number of correct reactions, which was the total number entering the lit arm of the 20 trials each day; the total reaction duration, which rats spent completing the 20 trials each day and the number of initiative avoidance responses, which was the number of escape responses of the rats within the $5 \mathrm{sec}$ prior to the arms being electrified.

Splenectomy surgery. Splenectomy surgery was performed using the method reported in our previous study (11). Briefly, the rats were initially placed in a closed box with an airflow of $3 \%$ isoflurane for $5 \mathrm{~min}$. Anesthesia was then administered through a mask using $2 \%$ isoflurane. A 14-gauge catheter was inserted through the glottis. The rats were artificially ventilated, through endotracheal intubation, with room air supplemented with $2 \mathrm{l} / \mathrm{min}$ oxygen and $2 \%$ isoflurane for $2 \mathrm{~h}$ (22). During the anesthesia, the gas concentrations and respiratory rates (RR; breaths per min)were continuously monitored using a multi-function monitor (Datex-Ohmeda, Helsinki, Finland) (Table I). Rectal temperature was maintained at $37 \pm 0.5^{\circ} \mathrm{C}$. In addition, heart rate (HR), mean arterial blood pressure (MAP) and pulse oximeter oxygen saturation (SpO2) were measured continuously through a femoral artery catheter (Table I). Under anesthesia, a small incision was made in the upper left quadrant through the skin and muscle wall. The spleen was mobilized, isolated and removed. The wound was infiltrated with $0.25 \%$ bupivacaine and then closed with sterile sutures. The rats in the normal control group received $40 \%$ oxygen for $2 \mathrm{~h}$ in a gas chamber without surgery.

2-DE and MALDI-TOF-MS. Hippocampal tissue (250 mg) was suspended in $1 \mathrm{ml}$ of $8 \mathrm{M}$ urea, $2 \mathrm{M}$ sulfocarbamide, $20 \mathrm{mM}$ Tris-HCl, $1 \mathrm{mM}$ CHAPS, $40 \mathrm{mM}$ EDTA, $65 \mathrm{mM}$ dithiothreitol, $1 \mathrm{mM}$ phenylmethylsulfonyl fluoride, $0.025 \mathrm{mM}$ RNase, $0.05 \mathrm{mM}$ DNase and $1 \mathrm{mM} \mathrm{NaF}$. The suspension was sonicated for $\sim 30 \mathrm{sec}$ and centrifuged at $150,000 \mathrm{x} g$ for $45 \mathrm{~min}$. The protein concentration in the supernatant was examined using the Coomassie blue method (23). In first dimensional isoelectric focusing, 1,000 $\mu \mathrm{g}$ of each sample was loaded into immobilized $\mathrm{pH}$ 3-10 nonlinear gradient strips $(18 \mathrm{~cm})$. After $12 \mathrm{~h}$ of reswelling at $30 \mathrm{~V}$, voltages of $100,500,1,000$ and 3,000 V were administered for $1 \mathrm{~h}$ each and $8,000 \mathrm{~V}$ for $6 \mathrm{~h}$. The second dimensional separation was performed using $12 \%$ sodium dodecyl sulfate-polyacrylamide gels (Sangon Biotech Shanghai Co., Ltd, Shanghai, China) (24). Following staining of the gels with colloidal Coomassie blue (25), the gels were scanned using a Umax PowerLook II scanner and Adobe Photoshop 8.0 image software (Adobe Systems Inc., San Jose,. CA, USA), and the images were analyzed using ETTAN ImageMaster 2D Elite 4.01 software (GE Healthcare, Amersham, UK). This software was used for matching and quantitative analysis of the protein spots on the gels. The average gel was constructed as a representative gel for the three hippocampal samples acquired from each group of rats. The average mode of background subtraction was used for normalization of the intensity volume that indicates the protein concentration or the quantity on each spot. The average 


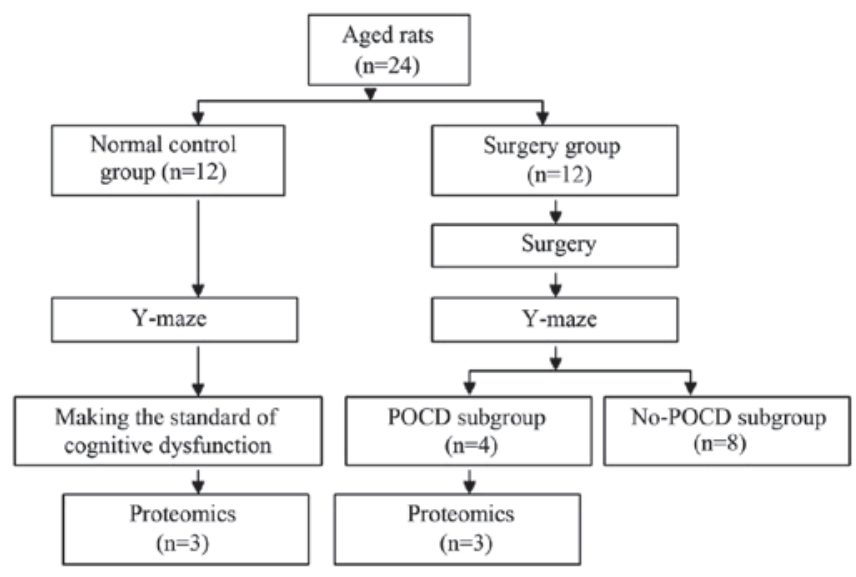

Figure 1. Flow chart detailing the experimental groups and steps performed. POCD, postoperative cognitive dysfunction.
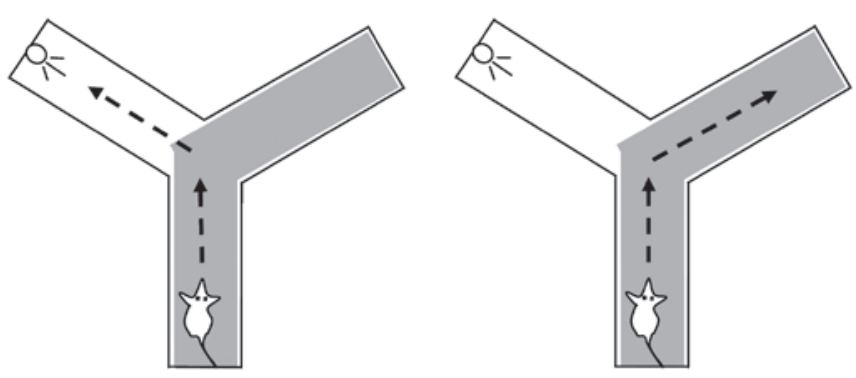

Figure 2. Learning and spatial memory assessment using a Y-maze. Individual cohorts of rats were assessed in the Y-maze apparatus to determine the trial number at which the rat entered into the lit, unshocked arm in $9 / 10$ consecutive trials. The left image indicates a correct reaction and the right image indicates an error reaction.

gel was then used for determination of the existence of differences in the protein expression levels between each group. A value of 2.0 indicated a 2 -fold increase and 0.5 indicated a 2 -fold reduction (26-29). Biologically relevant differences were defined as changes $>2$-fold.

MALDI-TOF-MS analysis was performed, as described previously (25-29). The valuable spots in the coomassie blue-stained gels were assessed. The extracts were redissolved in $1 \mu \mathrm{l}$ extraction buffer and $1 \mu 1$ matrix solution ( $\alpha$-acyano-4-hydroxycinnamic acid; Sangon Biotech Shanghai Co., Ltd) and targeted onto a MALDI-TOF plate. Following drying the samples completely onto the targeting plate, MALDI-TOF/MS was performed using a Voyager-DE STR mass spectrometer (Applied Biosystems, Foster City, CA, USA) equipped with delay ion extraction. Mass spectra were obtained over a mass range of 800-3,000 Da. For the identification of proteins, peptide mass fingerprinting data were used to search against the Mascot database (http://www.matrixscience. com) at the School of Life (Central South University). Peptide matching and protein identification were performed automatically, as described previously (26-29). A Mascot score $>58$ was considered to indicate statistical significance $(\mathrm{P}<0.05)$.

Reverse transcription quantitative polymerase chain reaction (RT-qPCR) for astrocyte-associated proteins. To confirm the differential protein expression based on MALDI-TOF-MS, the mRNA expression levels of the proteins of interest were detected by RT-qPCR. Total RNA from the hippocampus was isolated using the RNeasy plus mini kit (Qiagen, Valencia, CA, USA), according to the manufacturer's instructions. Prior to RT, the total RNA was treated to remove genomic DNA using a DNA-free kit (AM1906; Applied Biosystems). cDNA was synthesized using the Retroscript kit (AM1710; Applied Biosystems). RT-qPCR was performed using Power SYBR Green PCR master mix (Applied Biosystems). The rat $\beta$-actin gene was used as a homogenous standard. The running protocol extended to 40 cycles consisting of $95^{\circ} \mathrm{C}$ for $15 \mathrm{sec}$ and $60^{\circ} \mathrm{C}$ for $1 \mathrm{~min}$ using an Applied Biosystems 7500 Fast Real-time PCR system. The primers were designed using Primer 5.0 software (Premier Biosoft International, Palo Alto, CA, USA; Table II).

The relative quantity of the target gene present was calculated based on the expression of $\beta$-actin in the endogenous control. The mean cycle threshold $(\mathrm{Ct})$ values and standard deviations were calculated. To calibrate the analysis, the value obtained from the control rats was used. The factor difference was also calculated using the standard relative quantitative method ( $2^{-\Delta \Delta C T}$ method) $(30,31)$.

Statistical analysis. All summary data are reported as the mean \pm standard error of the mean. The results of the present study were processed using SPSS 17.0 statistical software (SPSS, Inc., Chicago, IL, USA). The total reaction time in the $\mathrm{Y}$ maze was analyzed using a repeated measures analysis of variance (ANOVA) with Bonferroni's post-hoc test. The number of correct reactions and initiative avoidance occurrences were examined using a non-parametric Mann-Whitney U test. The $\mathrm{RR}, \mathrm{HR}$ and MAP values during surgery were compared using a repeated measures ANOVA with Bonferroni's post-hoc test. The gel electrophoresis and RT-qPCR results were analyzed using Student's t-test. $\mathrm{P}<0.05$ was considered to indicate a statistically significant difference.

\section{Results}

Surgery with inhaled anesthesia impairs the cognitive function of aged rats. In the present study, a Y-maze test was used to evaluate cognitive function (1). A decrease of correct reactions and initiative avoidance number, and an increase in total reaction time implied deteriorating cognitive function. The findings demonstrated that the number of correct reactions in the surgery group were $8.90 \pm 1.09$ and 9.47 \pm 2.46 (24 and $48 \mathrm{~h}$, respectively) following surgery, which was significantly lower compared with the control group $(\mathrm{P}<0.05$; Fig. $3 \mathrm{~A})$. The number of initiative avoidance occurrences in the surgery group were $1.20 \pm 0.59$ and $2.07 \pm 1.01$ ( $24 \mathrm{~h}$ and $48 \mathrm{~h}$, respectively) following surgery, which was also significantly lower compared with the control group $(\mathrm{P}<0.05$; Fig. 3B). These findings demonstrated that surgery with inhaled anesthesia impaired the cognitive functions of aged rats at an early stage.

Surgery with inhaled anesthesia alters the protein profile of the hippocampus in aged rats with POCD. The protein expression profile of the hippocampus was assessed using MALDI-TOF-MS. The levels of 21 proteins in the hippocampus of aged rats with POCD were markedly altered, 
Table I. Vital signs of the rats during and after splenectomy surgery.

\begin{tabular}{llcccc}
\hline Group & Index & 10 min preoperative & 10 min operative & 20 min operative & 10 min postoperative \\
\hline Control & RR (bpm) & $82.20 \pm 3.35$ & $72.06 \pm 4.68$ & $71.33 \pm 3.29$ & $78.50 \pm 2.67$ \\
& HR (bpm) & $374.83 \pm 11.70$ & $359.83 \pm 16.49$ & $362.35 \pm 20.11$ & $365.00 \pm 16.07$ \\
& MAP $(\mathrm{mmHg})$ & $95.33 \pm 10.17$ & $83.83 \pm 10.32$ & $85.29 \pm 13.25$ & $88.67 \pm 7.23$ \\
& SpO2 $(\%)$ & $97.17 \pm 1.48$ & $97.50 \pm 1.64$ & $97.27 \pm 1.06$ & $97.83 \pm 1.16$ \\
Surgery & RR (bpm) & $80.00 \pm 4.70$ & $71.50 \pm 6.78$ & $73.75 \pm 7.69$ & $75.60 \pm 8.41$ \\
& HR (bpm) & $372.57 \pm 12.11$ & $348.28 \pm 11.33$ & $355.88 \pm 13.68$ & $361.78 \pm 12.52$ \\
& MAP (mmHg) & $92.21 \pm 8.32$ & $83.21 \pm 9.07$ & $85.64 \pm 8.33$ & $87.14 \pm 8.37$ \\
& SpO2 $(\%)$ & $97.93 \pm 1.07$ & $97.78 \pm 1.31$ & $97.65 \pm 1.08$ & $97.42 \pm 1.15$ \\
\hline
\end{tabular}

No statistical difference was observed in the RR, MAP and $\mathrm{SpO}_{2}$ between the rats in control group and surgery group $(\mathrm{P}>0.05)$. RR; respiratory rate; $\mathrm{HR}$, heart rate; MAP, mean arterial blood pressure; $\mathrm{SpO}_{2}$, oxygen saturation; bpm, beats per minute.

Table II. Primers used for reverse transcription quantitative polymerase chain reaction.

\begin{tabular}{llc}
\hline Gene & \multicolumn{1}{c}{ Primer } & Amplicon length(bp) \\
\hline Glutamate dehydrogenase & Forward: GCTCTGGACTCTTCCCAACA & 115 \\
Glutamine synthetase & Reverse: AAATGCCACACGCCTACTTC & 119 \\
Fatty acid binding protein 7, brain & Forward: CGCTCTTCGTCTCGTTCTC & 133 \\
$\beta$-actin & Reverse: CTGCTTGATGCCTTTGTTCA & 181 \\
& Forward: GAAGGGCAAGGATGGTAGATG & Reverse: ACCGTTGGTTTGGTCACATT \\
\hline
\end{tabular}

A

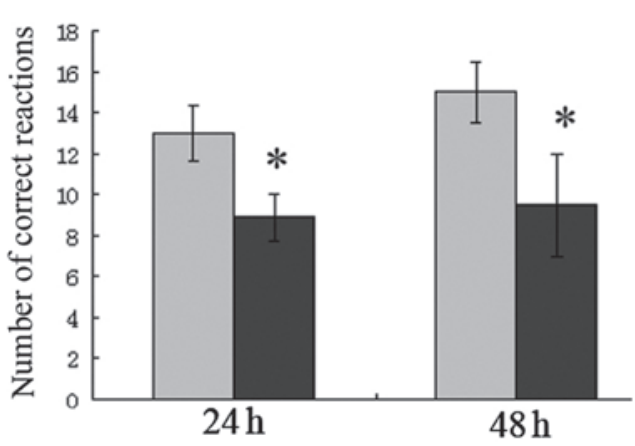

B

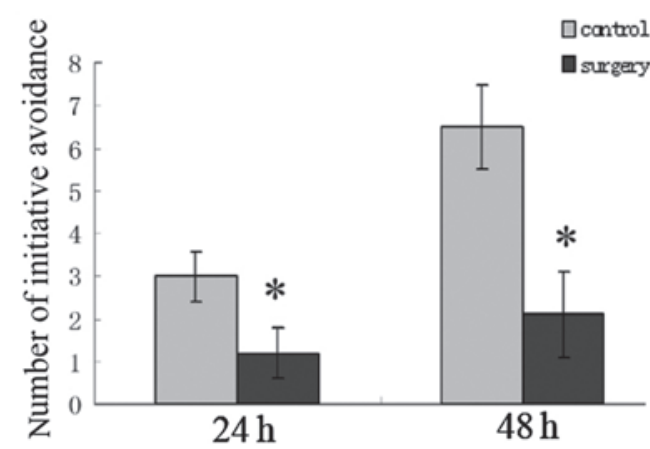

Figure 3. Surgery impairs the cognitive functions of aged rats during the first 2 days postoperatively. In the Y-maze test, the number of (A) correct reactions and (B) initiative avoidances were used to demonstrate cognitive function. Compared with the control group, the number of correct reactions in the surgery group increased and the number of initiative avoidances decreased 24 and $48 \mathrm{~h}$ after isoflurane anesthesia $\left({ }^{*} \mathrm{P}<0.05\right.$, vs. control).

compared with the normal control. These proteins included dynamin-1, superoxide dismutase, glutamine synthetase and coronin-1A (Table III, Fig. 4). Further functional clustering revealed that three proteins were closely involved in synaptic plasticity, four in oxidative stress, six in energy production three in neuroinflammation and two in glutamate metabolism. The protein expression levels were downregulated, with regard to synaptic plasticity, oxidative stress, energy production and glutamate metabolism; however, the protein expression levels associated with neuroinflammation were upregulated in the POCD rats.
Astrocytes are the predominant type of cell in the hippocampus, with important roles in supporting neurons. Thus, from the identified differentially expressed proteins, three proteins associated with astrocytes were selected [fatty acid binding protein 7, brain (FABP7) (32), glutamate dehydrogenase 1 (GLUD1) (33) and glutamine synthetase (GS) (34)] to confirm the reliability of the data from the MALDI-TOF-MS assessment. It was identified that the mRNAs of FABP-7 and GLUD increased in aged rats with POCD and the mRNAs of GS decreased, closely corresponding to the changes observed in the MALDI-TOF-MS data $(\mathrm{P}<0.05$; Fig. 5). 


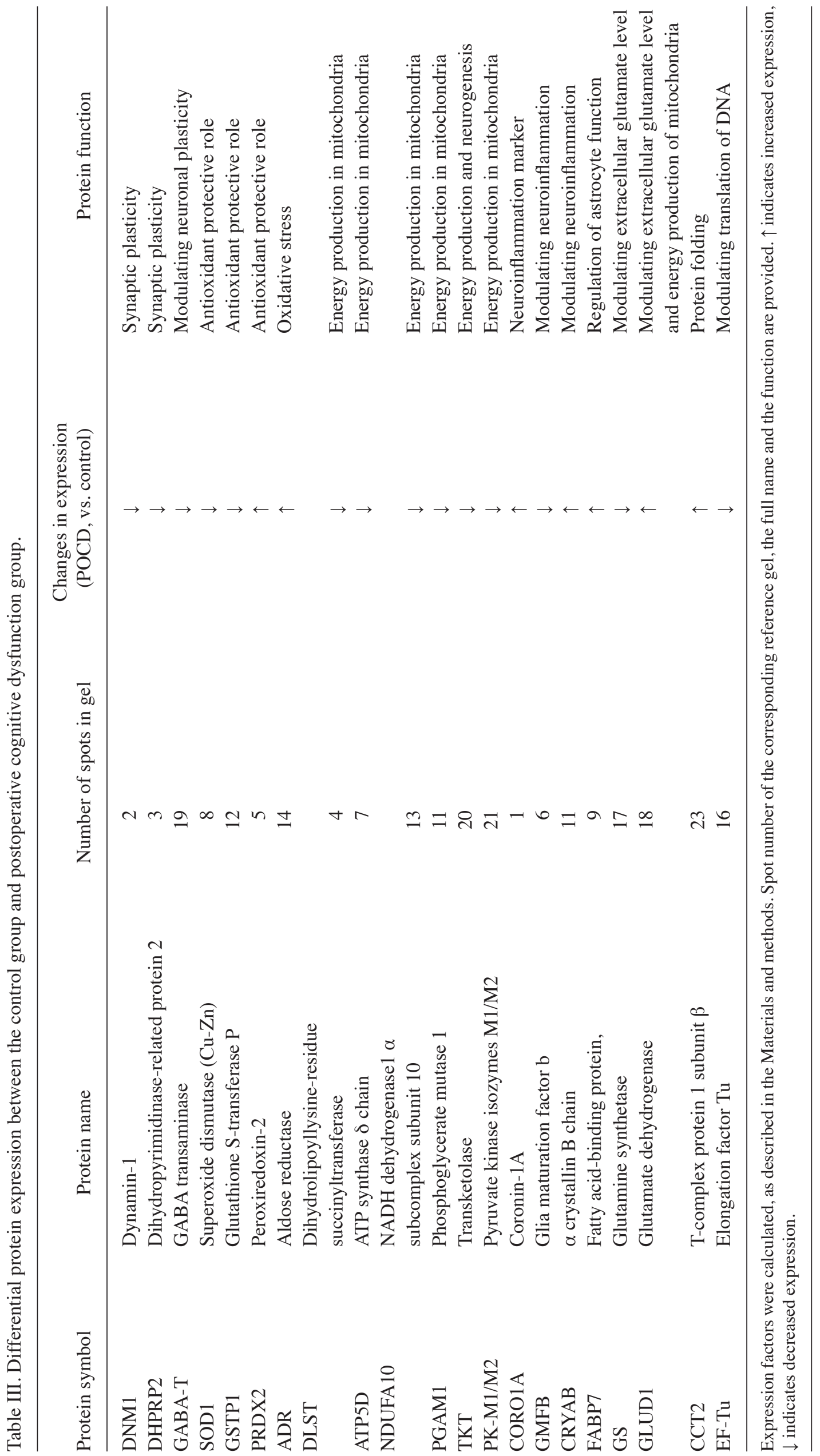




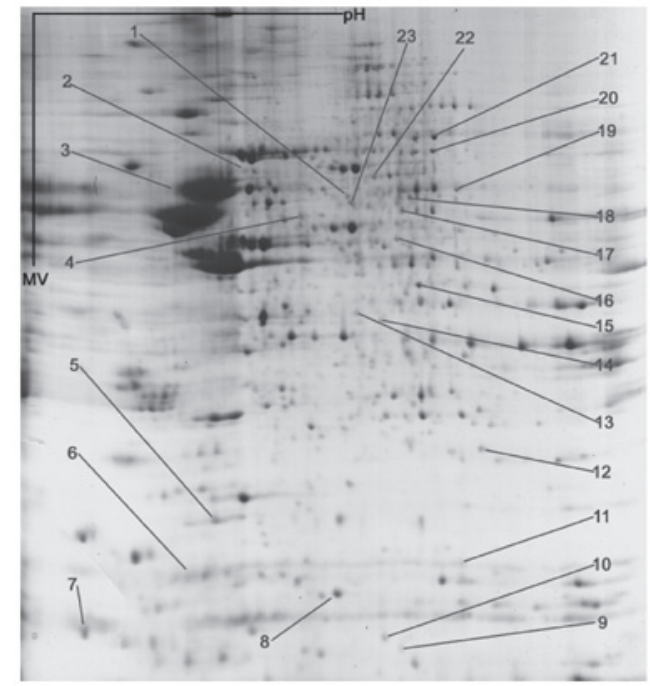

Figure 4. Representative image of two-dimensional gel electrophoresis. Protein separation was performed with immobilized non-linear $\mathrm{pH}$ 3-10 gradient gel strips and subsequent sodium dodecyl sulfate-polyacrylamide gel electrophoresis in a $12.5 \%$ matrix followed by Coomassie blue staining. Spot numbers were provided for all the spot-cut proteins, which were identified using a matrix-assisted laser desorption/ionization-time-of-flight mass spectrometer.

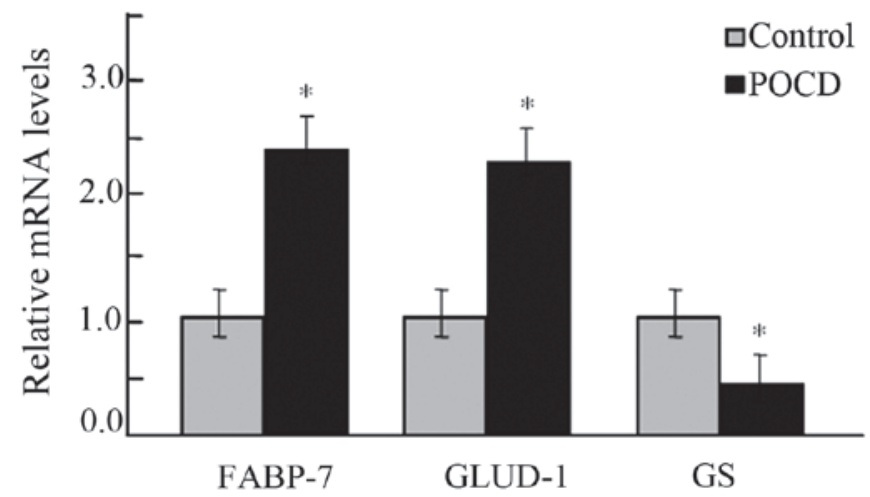

Figure 5. Comparison of the gene expression levels of FABP7, GLUD1 and GS in the hippocampus. Values are expressed as the mean \pm standard error of the mean of three rats. " $\mathrm{P}<0.05$, vs. control. The graph was constructed using Igor Pro 4.09A software. FABP7, fatty acid binding protein 7, brain, GLUD-1, glutamate dehydrogenase 1; GS, glutamine synthetase; POCD, postoperative cognitive dysfunction.

\section{Discussion}

In the present study, the protein profile of the hippocampi in aged rats with POCD and normal aged rats were screened. A total of 21 proteins were significantly altered in aged rats with POCD compared with normal aged rats. These proteins were functionally clustered in association with synaptic plasticity, oxidative stress, energy production, glutamate metabolism and neuroinflammation. These data provided important indications that the hippocampus is functionally important in the POCD of aged rats.

POCD is usually detected among aged patients following surgery. It was initially reported by Bedford in 1955 (35). In the present study, the cognitive function of aged rats was initially assessed with or without surgery using a Y-maze. The number of correct reactions and the number of initiative avoidance occurrences in the surgery group were significantly lower compared with the control group $(\mathrm{P}<0.05)$. These results suggested that surgery with inhaled anesthesia impaired the cognitive function of aged rats at an early stage. Based on these findings, changes in the protein expression profile of the hippocampi of aged rats with POCD was assessed. Compared with the normal control, 14 proteins increased in the aged rats with POCD and seven proteins decreased (Table II). PubMed (http:// http:// www.ncbi.nlm.nih.gov/pubmed/) was used to search for useful information using key words. Among the 21 proteins, three proteins, DNM1 (36-38), DHPRP2 (39) and GABA-T $(40,41)$ were involved in synaptic plasticity and their expression were decreased in aged rats with POCD. A total of four proteins, SOD1 $(42,43)$, glutathione S-transferase P $(44,45)$, peroxiredoxin 2 (46) and ADR (47) were associated with oxidative stress. In addition, six proteins, dihydrolipoyllysine-residue succinyltransferase (48), ATP synthase $\delta$ chain (49), NADH dehydrogenase $1 \alpha(50)$, phosphoglycerate mutase 1 (51), transketolase (52) and pyruvate kinase isozymes M1/M2 (53), were involved in energy production and their expression levels were decreased in the aged rats with POCD. A total of three proteins, coronin-1A (54), glia maturation factor $b$ (55), $\alpha$ crystallin B chain (56) were involved in neuroinflammation. These findings suggested that surgery induced neuronal damage in aged rats with POCD. Neuroinflammation and oxidative stress were important in neuronal damage and the data were consistent with previously reported results $(4,11-13,20,57)$. Chen et al (20) found that aged patients with POCD had a smaller volume hippocampus and the size of the hippocampus was negatively correlated with the cognitive function of aged patients following surgery. It has been found that surgery induced increased neuroinflammation in mice and aged rats $(4,11,12)$, corresponding to cognitive dysfunction. In addition, An et al (57) found that surgical trauma induced oxidative stress in rats with POCD (57). Notably, the expression of FABP7 (32), a modulator of astrocyte function, was higher in aged rats with POCD. At the same time, GS (58) and GLUD1 (33,59-61), which are two astrocytic enzymes modulating the level of extracellular glutamate, were also changed in aged rats with POCD. These findings suggested that astrocytes are important in the mechanism underlying POCD, and astrocytes may offer a novel direction in the investigation of POCD.

The present study did not distinguish the effect of surgery in POCD from the anaesthetic agent, as our previous study demonstrated that anesthesia and surgery can result in POCD. It has been confirmed that surgery, rather than anesthetic agents lead to long-term changes in exploratory behavior (62). It is disputed whether the mechanism underlying POCD is associated with surgery and/or anesthesia, however, it is considered to be a multi-factorial process. Further investigation is required to discriminate each component of the entire process.

\section{Acknowledgements}

The authors would like to thank all those who assisted with this study, particularly Professor Jianbin Tong, who provided technical assistance and critically edited the manuscript. 


\section{References}

1. Yan XB, Ouyang W, Li G and Duan KM: Involvement of neuronal nitric oxide synthase in cognitive impairment in isoflurane-treated rats. Neurosci Lett 506: 240-244, 2012.

2. Ramaiah R and Lam AM: Postoperative cognitive dysfunction in the elderly. Anesthesiol Clin 27: 485-496, 2009.

3. Monk TG and Price CC: Postoperative cognitive disorders. Curr Opin Crit Care 17: 376-381, 2011.

4. Terrando N, Monaco C, Ma D, Foxwell BM, Feldmann M and Maze M: Tumor necrosis factor-alpha triggers a cytokine cascade yielding postoperative cognitive decline. Proc Natl Acad Sci USA 107: 20518-20522, 2012.

5. Rosczyk HA, Sparkman NL and Johnson RW: Neuroinflammation and cognitive function in aged mice following minor surgery. Exp Gerontol 43: 840-846, 2008.

6. Culley DJ, Baxter MG, Yukhananov R and Crosby G: Long-term impairment of acquisition of a spatial memory task following isoflurane-nitrous oxide anesthesia in rats. Anesthesiology 100 : 309-314, 2004

7. Culley DJ, Baxter M, Yukhananov R, Crosby G, Culley DJ, Baxter M, Yukhananov R and Crosby G: The memory effects of general anesthesia persist for weeks in young and aged rats. Anesth Analg 96: 1004-1009, 2003

8. Culley DJ, Baxter MG, Crosby CA, Yukhananov R and Crosby G: Impaired acquisition of spatial memory 2 weeks after isoflurane and isoflurane-nitrous oxide anesthesia in aged rats. Anesth Analg 99: 1393-1397, 2004

9. Hudson AE and Hemmings HC Jr: Are anaesthetics toxic to the brain? Br J Anaesth 107: 30-37, 2011.

10. Rasmussen LS, Johnson T, Kuipers HM, Kristensen D, Siersma VD, Vila P, Jolles J, Papaioannou A, Abildstrom H, Silverstein JH, Bonal JA, Raeder J, Nielsen IK, Korttila K, Munoz L, Dodds C, Hanning CD and Moller JT: ISPOCD2 (international study of postoperative cognitive dysfunction) investigators: does anaesthesia cause postoperative cognitive dysfunction? A randomised study of regional versus general anaesthesia in 438 elderly patients. Acta Anaesthesiol Scand 47: 260-266, 2003.

11. He HJ, Wang Y, Le Y, Duan KM, Yan XB, Liao Q, Liao Y, Tong JB, Terrando N and Ouyang W: Surgery upregulates high mobility group box-1 and disrupts the blood-brain barrier causing cognitive dysfunction in aged rats. CNS Neurosci Ther 18 994-1002, 2012.

12. Wang Y, He HJ, Li D, Zhu WJ, Duan KM, Le Y, Liao Y and Ouyang W: The role of the TLR4 signaling pathway in cognitive deficits following surgery in aged rats. Mol Med Rep 7: $1137-1142,2013$.

13. Terrando N, Eriksson LI, Ryu JK, Yang T, Monaco C, Feldmann M, Jonsson Fagerlund M, Charo IF, Akassoglou K and Maze M: Resolving postoperative neuroinflammation and cognitive decline. Ann Neurol 70: 986-995, 2011.

14. Evered L, Scott DA, Silbert B and Maruff P: Postoperative cognitive dysfunction is independent of type of surgery and anesthetic. Anesth Analg 112: 1179-1185, 2011.

15. Bi FF, Huang C, Tong JB, Qiu G, Huang B, Wu Qx, Li F, Xu ZS, Xia XG and Zhou HX: Reactive astrocytes secrete Lcn 2 to assist neurons in degeneration. Proc Natl Acad Sci USA 110: 4069-4074, 2013.

16. Dede AJ, Wixted JT, Hopkins RO and Squire LR: Hippocampal damage impairs recognition memory broadly, affecting both parameters in two prominent models of memory. Proc Natl Acad Sci USA 1: 6577-6582, 2013

17. Da Silva WC, Cardoso G, Bonini JS, Benetti F and Izquierdo I: Memory reconsolidation and its maintenance depend on L-voltage-dependent calcium channels and CaMKII functions regulating protein turnover in the hippocampus. Proc Natl Acad Sci USA 110: 6566-6570, 2013.

18. Buckner RL: Memory and executive function in aging and $\mathrm{AD}$ : multiple factors that cause decline and reserve factors that compensate. Neuron 44: 195-208, 2004.

19. Jagust W: Vulnerable neural systems and the borderland of brain aging and neurodegeneration. Neuron 77: 219-234, 2013.

20. Chen MH, Liao Y, Rong PF, Hu R, Lin GX and Ouyang W: Hippocampal volume reduction in elderly patients at risk for postoperative cognitive dysfunction. J Anesth 27: 487-492, 2013.

21. Chen SQ, Wang PJ, Ten GJ, Zhan W, Li MH and Zang FC: Role of myo-inositol by magnetic resonance spectroscopy in early diagnosis of Alzheimer's disease in APP/PS1 transgenic mice. Dement Geriatr Cogn Disord 28: 558-566, 2009.
22. Covasala O, Stirn SL, Albrecht S, De Col R and Messlinger K Calcitonin gene-related peptide receptors in rat trigeminal ganglion do not control spinal trigeminal activity. J Neurophysiol 108 431-440, 2012.

23. Krauspe $R$ and Scheer A: Coomassie brilliant blue G-250 dye-binding technique for determination of autolytic protein breakdown in Euglena gracilis and comparison to other methods of autolysis measurement. Anal Biochem 153: 242-250, 1986.

24. Oguri T, Takahata I, Katsuta K, Nomura E, Hidaka M and Inagaki $\mathrm{N}$ : Proteome analysis of rat hippocampal neurons by multiple large gel two-dimensional electrophoresis. Proteomics 2 666-672, 2002

25. Fountoulakis M and Gasser R: Proteomic analysis of the cell envelope fraction of Escherichia coli. Amino Acids 24: 19-41,2003.

26. Opii WO, Joshi G, Head E, Milgram NW, Muggenburg BA, Klein JB, Pierce WM, Cotman CW and Butterfield DA: Proteomic identification of brain proteins in the canine model of human aging following a long-term treatment with antioxidants and a program of behavioral enrichment: relevance to Alzheimer's disease. Neurobiol Aging 29: 51-70, 2008.

27. Berndt P, Hobohm U and Langen H: Reliable automatic protein identification from matrix-assisted laser desorption/ionization mass spectrometric peptide fingerprints. Electrophoresis 20: 3521-3526, 1999

28. Nikolov M, Schmidt C and Urlaub H: Quantitative mass spectrometry-based proteomics. Methods Mol Biol 893: 85-100, 2012.

29. Nagappan A, Park HS, Park KI, Kim JA, Hong GE, Kang SR, Zhang J, Kim EH, Lee WS, Won CK and Kim GS: Proteomic analysis of differentially expressed proteins in vitamin C-treated AGS cells. BMC Biochem 14: 24, 2013.

30. Nolan T, Hands RE and Bustin SA: Quantification of mRNA using real-time RT-PCR. Nat Protoc 1: 1559-1582, 2006.

31. Livak KJ and Schmittgen TD: Analysis of relative gene expression data using real-time quantitative PCR and the 2 (-Delta Delta C(T)) Methods 25: 402-408, 2001

32. Kipp M, Clarner T, Gingele S, Pott F, Amor S, van der Valk P and Beyer C: Brain lipid binding protein (FABP7) as modulator of astrocyte function. Physiol Res 60 Suppl 1: 49-60, 2011.

33. Aubrecht J and Schomaker S: Serum glutamate dehydrogenase as a potential biomarker of mitochondrial dysfunction. Toxico Sci 134: 223, 2013

34. Butterfield DA, Hensley K, Cole P, et al: Oxidatively induced structural alteration of glutamine synthetase assessed by analysis of spin label incorporation kinetics: relevance to Alzheimer's disease. J Neurochem 68: 2451-2457, 1997.

35. Bedford PD: Adverse cerebral effects of anaesthesia on old people. Lancet 269: 259-263, 1955

36. Mallozzi C, D'Amore C, Camerini S, Macchia G, Crescenzi M, Petrucci TC and Di Stasi AM: Phosphorylation and nitration of tyrosine residues affect functional properties of Synaptophysin and Dynamin I, two proteins involved in exo-endocytosis of synaptic vesicles. Biochim Biophys Acta 1833: 110-121, 2013.

37. Merriam LA, Baran CN, Girard BM, Hardwick JC, May V and Parsons RL: Pituitary adenylate cyclase 1 receptor internalization and endosomal signaling mediate the pituitary adenylate cyclase activating polypeptide-induced increase in guinea pig cardiac neuron excitability. J Neurosci 33: 4614-4422, 2013.

38. Yamada H, Abe T, Satoh A, Okazaki N, Tago S, Kobayashi K, Yoshida Y, Oda Y, Watanabe M, Tomizawa K, Matsui $\mathrm{H}$ and Takei K: Stabilization of actin bundles by a dynamin $1 /$ cortactin ring complex is necessary for growth cone filopodia. J Neurosci 33: 4514-4526, 2013.

39. Koide T, Aleksic B, Ito Y, Usui H, Yoshimi A, Inada T, Suzuki M, Hashimoto R, Takeda M, Iwata N and Ozaki N: A two-stage case-control association study of the dihydropyrimidinase-like 2 gene (DPYSL2) with schizophrenia in Japanese subjects. J Hum Genet 55: 469-472, 2010.

40. Wang QP, Jammoul F, Duboc A, Gong J, Simonutti M, Dubus E, Craft CM, Ye W, Sahel JA and Picaud S: Treatment of epilepsy: the GABA-transaminase inhibitor, vigabatrin, induces neuronal plasticity in the mouse retina. Eur J Neurosci 27: 2177-2187, 2008.

41. Hwang IK, Kim DW, Yoo KY, Kim DS, Kim KS, Kang JH, Choi SY, Kim YS, Kang TC and Won MH: Age-related changes of gamma-aminobutyric acid transaminase immunoreactivity in the hippocampus and dentate gyrus of the Mongolian gerbil. Brain Res 1017: 77-84, 2004

42. Wootz H, Fitzsimons-Kantamneni E, Larhammar M, Rotterman TM, Enjin A, Patra K, André E, Van Zundert B, Kullander K and Alvarez FJ: Alterations in the motor neuron-renshaw cell circuit in the Sod1 (G93A) mouse model. J Comp Neurol 521: 1449-1469, 2013. 
43. Kang SH, Li Y, Fukaya M, Lorenzini I, Cleveland DW, Ostrow LW, Rothstein JD and Bergles DE: Degeneration and impaired regeneration of gray matter oligodendrocytes in amyotrophic lateral sclerosis. Nat Neurosci 16: 571-579, 2013.

44. Castro-Caldas M, Carvalho AN, Rodrigues E, Henderson C, Wolf CR and Gama MJ: Glutathione S-transferase pi mediates MPTP-induced c-Jun N-terminal kinase activation in the nigrostriatal pathway. Mol Neurobiol 45: 466-477, 2012.

45. Korff A, Pfeiffer B, Smeyne M, Kocak M, Pfeiffer RF and Smeyne RJ: Alterations in glutathione S-transferase pi expression following exposure to $\mathrm{MPP}^{+}$-induced oxidative stress in the blood of Parkinson's disease patients. Parkinsonism Relat Disord 17: 765-768, 2011.

46. Sánchez-Font MF, Sebastià J, Sanfeliu C, Cristòfol R, Marfany G and Gonzàlez-Duarte R: Peroxiredoxin 2 (PRDX2), an antioxidant enzyme, is under-expressed in Down syndrome fetal brains. Cell Mol Life Sci 60: 1513-1523, 2003.

47. Tang WH, Martin KA and Hwa J: Aldose reductase, oxidative stress and diabetic mellitus. Front Pharmacol 3: 87, 2012.

48. Takase C, Nakano K, Ohta S, Nakagawa S and Matuda SY: Different distribution of dihydrolipoamide succinyltransferase, dihydrolipoamide acetyltransferase and ATP synthase beta-subunit in monkey brain. In Vivo 10: 495-501, 1996.

49. Ko YH, Pan W, Inoue C and Pedersen PL: Signal transduction to mitochondrial ATP synthase: evidence that PDGF-dependent phosphorylation of the delta-subunit occurs in several cell lines, involves tyrosine and is modulated by lysophosphatidic acid. Mitochondrion 1: 339-348, 2002.

50. Adam-Vizi V and Tretter L: The role of mitochondrial dehydrogenases in the generation of oxidative stress. Neurochem Int 62 : 757-763, 2013.

51. Batke J, Nazaryan KB and Karapetian NH: Complex of brain D-phosphoglycerate mutase and gamma enolase and its reactivation by D-glycerate 2,3-bisphosphate. Arch Biochem Biophys 264: 510-518, 1988.

52. Zhao Y, Pan X, Zhao J, Wang Y, Peng Y and Zhong C: Decreased transketolase activity contributes to impaired hippocampal neurogenesis induced by thiamine deficiency. J Neurochem 111: 537-546, 2009
53. Tolle SW, Dyson RD, Newburgh RW and Cardenas JM: Pyruvate kinase isozymes in neurons, glia, neuroblastoma and glioblastoma. J Neurochem 27: 1355-1360, 1976.

54. Ahmed Z, Shaw G, Sharma VP, Yang C, McGowan E and Dickson DW: Actin-binding proteins coronin-1a and IBA-1 are effective microglial markers for immunohistochemistry. J Histochem Cytochem 55: 687-700, 2007.

55. Zaheer A, Zaheer S, Sahu SK, Knight S, Khosravi H, Mathur SN and Lim R: A novel role of glia maturation factor: induction of granulocyte-macrophage colony-stimulating factor and pro-inflammatory cytokines. J Neurochem 101: 364-376, 2007.

56. Shao W, Zhang SZ, Tang M, Zhang XH, Zhou Z, Yin YQ, Zhou QB, Huang YY, Liu YJ, Wawrousek E, Chen T, Li SB, Xu M, Zhou JN, $\mathrm{Hu} \mathrm{G}$ and Zhou JW: Suppression of neuroinflammation by astrocytic dopamine D2 receptors via $\alpha B$-crystallin. Nature 494: 90-94, 2013.

57. An LN, Yue Y, Guo WZ, Miao YL, Mi WD, Zhang H, Lei ZL, Han SJ and Dong L: Surgical trauma induces iron accumulation and oxidative stress in a rodent model of postoperative cognitive dysfunction. Biol Trace Elem Res 151: 277-283, 2013.

58. Cooper AJ: Possible treatment of end-stage hyperammonemic encephalopathy by inhibition of glutamine synthetase. Metab Brain Dis 28: 119-125, 2013.

59. Plaitakis A, Zaganas I and Spanaki C: Deregulation of glutamate dehydrogenase in human neurologic disorders. J Neurosci Res 91: 1007-1017, 2013.

60. Frigerio F, Karaca M, De Roo M, Mlynárik V, Skytt DM, Carobbio S, Pajęcka K, Waagepetersen HS, Gruetter R, Muller D and Maechler P: Deletion of glutamate dehydrogenase 1 (Glud1) in the central nervous system affects glutamate handling without altering synaptic transmission. J Neurochem 123: 342-348, 2012.

61. Skytt DM, Klawonn AM, Stridh MH, Pajęcka K, Patruss Y, Quintana-Cabrera R, Bolaños JP, Schousboe A and Waagepetersen HS: siRNA knock down of glutamate dehydrogenase in astrocytes affects glutamate metabolism leading to extensive accumulation of the neuroactive amino acids glutamate and aspartate. Neurochem Int 61: 490-497, 2012.

62. Hovens IB, Schoemaker RG, van der Zee EA, Heineman E, Nyakas C and van Leeuwen BL: Surgery-induced behavioral changes in aged rats. Exp Gerontol 48: 1204-1211, 2012. 